\title{
La Democracia, el Estado y el Patriotismo en
}

\author{
Unamuno
}

Democracy, State and Patriotism in Unamuno

Emanuel José Maroco dos Santos

Universidad de Salamanca emanuel.ejms.santos@gmail.com

\section{Resumen}

El Unamuno filósofo fue, ante todo y sobre todo, un intelectual comprometido con la realidad política, social y económica de finales del siglo XIX y principios del XX. En el presente artículo, procuraremos revisitar algunas de sus ideas políticas concernientes a los conceptos de democracia, Estado y patriotismo. Nos interesa saber cómo el insigne rector de la Universidad de Salamanca concibió la democracia que definió 
independientemente de la monarquía y de la república como formas legítimas de gobierno, así como ideó la realidad Estado, que siempre vio secular o laicamente a partir de la escisión entre el poder temporal - trono- y el espiritual - altar. En nuestros análisis, prestaremos igualmente especial atención a su concepción de patriotismo, que se erigió y configuró en una época en que los separatismos político-lingüísticos tendían a diluir la unidad nacional española.

Palabras clave: Unamuno, Democracia, Patriotismo, Estado.

\section{Abstract}

Unamuno the philosopher was, above all, an intellectual committed to the political, social and economic reality of the turn of the nineteenth to the twentieth century. In the present study, we revisit some of his political ideas concerning the concepts of democracy, the State and patriotism. We look at how the distinguished Rector of the University of Salamanca conceived of democracy, which he defined beyond the monarchy and the republic as legitimate forms of government, and how he regarded the reality of the State, which he always viewed as secular based on the division between temporal power - the throne- and spiritual power - the altar-. In our analysis we pay equal attention to his conception of patriotism, which was set up and configured at a time when political-linguistic separatisms tended to dilute national unity in Spain.

Key words: Unamuno, Democracy, Patriotism, State. 


\section{Introducción}

Nuestra intención es analizar, en las líneas que siguen, tres ideas políticas unamunianas que, por su densidad $y$ sentido, permiten todavía hoy comprender la realidad en que estamos ubicados. La comprensión de las concepciones unamunianas de «democracia», «Estado» $\mathrm{y}$ «patriotismo» no nos han de servir como mero análisis hermenéutico de la relación que dichos conceptos mantienen con la totalidad de la obra del autor o con la realidad política y social en que vivió. Nuestra intención no es ésa, sino la de revisitar su pensamiento como forma de comprender nuestra propia realidad sociopolítica que, en muchos aspectos, comulga con la de su realidad histórica. Asimismo, la elección de dichos conceptos no es casual ni fortuita, sino que se relaciona con la necesidad de repensar la realidad política, vislumbrando soluciones a los problemas a los que todavía hoy nos enfrentamos a pesar de que hayan transcurrido más de cien años con respecto a algunos textos unamunianos que aquí analizamos.

A Unamuno siempre le dolió la enfermedad moral de los políticos de su conturbada época histórica. En efecto, nada vio nuestro autor más lamentable que los actores de la política nacional, que, presos de la necesidad de la elección, de la reelección o del simple mantenimiento en el cargo, se sometían al gusto de sus electores, en vez de educarlos con vistas al bien común. Unamuno es, pues, como vieron muy 
bien Gómez Molleda (1986: 355) y Stephen Roberts (2007: 163), no un político, sino un «intelectual político». A don Miguel no le interesó, por lo menos en su madurez, alistarse en un partido político y ejercer desde allí su acción pública de transformación social, política y económica de su patria. Le interesó más bien, desde su cátedra en la secular universidad salmantina, hacer obra política y demagógica de dirección del pueblo. Y fue su interés por los problemas de su país el que hizo que Unamuno a lo largo de su extenso quehacer de publicista fuese concibiendo sus ideas de «democracia», «Estado»y «patriotismo».

En una España dividida entre la Monarquía y la República, como formas de legítimas de gobierno, don Miguel $-\mathrm{y}$ necesario es subrayar que fue nuestro autor quien tras su regreso a España proclamó la República desde el balcón del Ayuntamiento de Salamanca (Salcedo, 2005: 374-379)—, posicionándose paradójicamente fuera del ámbito de dichas formas de gobierno, siempre heridas por la contingencia, como él mismo afirmó (Unamuno, 1966: 1287), se comprometió, iy con qué entusiasmo!, con lo que había de ser una «democracia», que habría de cimentarse, ante y sobre todo, en un pueblo consciente de su propio destino. Y si miramos bien, su España finisecular decimonónica, con dos tercios de analfabetos absolutos (Delgado Criado, 1973: 45), no era particularmente halagüeña para la implantación de la misma, ya que ésta suponía una eficaz educación del pueblo a no ser que por 
democracia se concibiese un régimen político acéfalo donde el pueblo, el soberano, no fuese el guía de sí mismo. No nos extraña que la labor del «intelectual político» Unamuno fuese la de educar a su propio pueblo, para que él, animado en sus propias raíces culturales intrahistóricas, pudiese darse a sí mismo las leyes que lo deberían regir.

Otra idea política por la cual luchó incansablemente Unamuno fue por la separación entre el poder temporal y el espiritual. Para el rector salmantino, profundo conocedor de la historia española y europea, con Constantino se dio la unión del «Trono»y del «Altar», que, en el caso español, se consolidó a partir del odio y de la lucha contra el moro, que permitió la formación de la nacionalidad española. Sin embargo, don Miguel, lector asiduo del Nuevo Testamento, conocía bien la toma de posición político-religiosa de Jesucristo en lo que concierne a la necesaria división de los poderes temporal y espiritual, como lo demuestra su referencia a las expresiones bíblicas «Dad al César lo que es del César y a Dios lo que es de Dios» y «Mi reino no es de este mundo» que utiliza para justificar su propia toma de posición. En este aspecto, debe tenerse siempre presente que Unamuno criticó incansablemente la teoría jesuítica del reinado social de Jesucristo o del cristianismo social. Para don Miguel, ambas esferas, la civilidad y la religiosidad, eran necesarias y esencialmente distintas, tanto más cuanto que consideró que el «cristianismo» es antihistórico e 
individualista como tuvo oportunidad de subrayar en su obra de 1924 La agonía del cristianismo.

El último tema político que quisiéramos analizar es la concepción unamuniana de «patriotismo». Dicho concepto, en su acepción más directa y primaria, significa amor a la patria. Y si éste es su significado esencial, Unamuno no pudo dejar de percibir que, en su época finisecular decimonónica, los españoles no profesaban el sentimiento patriótico que deberían profesar y que, al contrario de lo que debería suceder, éstos estaban radicalmente arraigados a un regionalismo lingüístico-político separatista con respecto al conjunto del país. Pronto se apercibió de que gallegos, vizcaínos y catalanes sentían su patria sensitiva, la «patria chica», la que se recorre con la mirada, pero no sentían como suya la patria intelectiva, la patria grande, la que se aprender a amar cultivando el amor a la historia común que une a todos los españoles (Unamuno, 1966: 1288). Ante dicho hecho, Unamuno se propuso indagar los condicionantes históricos que han desencadenado la falta de patriotismo que afectaba a los españoles de dichas regiones $\mathrm{y}$, al hacerlo, verificó que la patria intelectiva, el amor a la historia común, se diluía en el «sentimiento cosmopolita universal», tendiendo a ser sustituida por éste. Para solucionarlo, propuso a los españoles que viajasen por todo el territorio nacional, ya que creía que conociéndose el cuerpo de la patria se aprendería a conocer y a amar el alma de la misma. 


\section{La democracia: la única forma moral de gobierno; una realidad política entre la Monarquía y la República}

(1) Suelo yo decir que en las pequeñas villas y en los distritos rurales de esta nuestra España, hay siempre por lo menos dos partidos, y son los antiequisistas que siguen a Zeda contra Equis, y los antizedistas, que siguen a Equis contra Zeda. Y nótese que no les llamo equisistas ni zedistas, porque son ellos esencial y fundamentalmente negativos. Más que seguir a uno, van contra el otro. $Y$ en general puede decirse que nuestros republicanos no son sino antimonárquicos, $\mathrm{y}$ no sino antirrepublicanos nuestros monárquicos (Unamuno, 1968a:490).

(2) ¿Qué es eso del cristianismo social? ¿Qué es eso del reinado social de Jesucristo, con que tanto nos marean los jesuítas? ¿Qué tiene que ver la cristiandad, la verdadera cristiandad, con la sociedad de aquí abajo, de la tierra? ¿Qué es eso de la democracia cristiana? (Unamuno, 1969b:334).

La primera constatación que Unamuno hizo fue la de que la realidad política española estaba, en el periodo finisecular, 
perniciosamente estructurada a partir de la oposición hacia algo. Para nuestro autor, los partidos políticos, en vez de estructurarse en torno a su identidad partidaria, lo hacían a partir de la oposición hacia otro partido político, en la medida en que, para don Miguel, como tuvo ocasión de subrayarlo en su ensayo «Los antipoliticistas», de 1910, cada partido político buscaba más ser antizedista que equisista o, al revés, más antiequisista que zedista. Directamente correlacionado con esta tendencia a forjar el concepto de identidad a partir de la oposición al de alteridad se yuxtapone el tema del fariseísmo político. Para Unamuno, fariseo significaba «hombre separado» o, si se quiere, «hombre de secta [...] [o] de partido» (Unamuno, 1971: 1221). No nos extraña, pues, que, a su juicio, el político fariseo español finisecular se preocupase más por el poder que por la gobernación misma (Unamuno, 1971: 1222). Fue por ello que, en su ensayo Demagogia, publicado el 19 de abril de 1922, Unamuno, refiriéndose a una visita que hizo al Palacio de la Zarzuela afirmó, contundentemente, su aversión a todos partidos políticos, que, preocupados tan sólo con las elecciones, se olvidaban de las necesidades reales del pueblo (Unamuno, 2003: 431). En lo que concierne al tema, cabría subrayar, tan sólo, que fue este mismo hecho lo que llevó a Unamuno a oponerse a todos los partidos políticos, afirmando su absoluta independencia con relación a los mismos; y de tal forma lo hizo que identificó su misión política, si se quiere, educativa o demagógica, con la insigne 
y sagrada misión de educar al pueblo español (Unamuno, 2003: 432).

Con respecto a las formas de gobierno, si se tiene en consideración su ensayo «La crisis del actual patriotismo español», de 1905, verificamos que Unamuno consideraba la Monarquía y la República como dos formas legítimas de gobierno, independientemente de sus ventajas y desventajas, afirmando, incluso, que dicha opción sólo «ten[ía] sentido [...] en un lugar y tiempo determinados» (Unamuno, 1966: 1287). De entre los inconvenientes que percibió en la Monarquía, en cuanto forma de gobierno, Unamuno no dejó de subrayar el hecho de que el Rey se considerase a sí mismo, antes de cualquier otra denominación, como Jefe del Ejército $y$, después, la frecuencia con que éste solía «ejercer poderes individuales», «salta[ndo] por encima de la [propia] Constitución» (Unamuno, 2003: 261). Ahora bien, pese al hecho de que nos sea sencillo acercar a Unamuno al movimiento republicano, ya que fue él mismo el que proclamó la República, en el año 1931, creemos que es más fructuoso aproximarlo al movimiento democrático, ya que, en la línea de Stephen Roberts (2007: 182) y de Paul Aubert (2005, 233), creemos que lo decisivo, dentro de su pensamiento político, radica en su afirmación del concepto de democracia. Por lo demás, si en algo puede resumirse la acción política o, si se quiere, educativa de Unamuno eso es sin duda en su deseo de formar un pueblo capaz de ser «el guía de su propio 
destino» (Gómez de la Torre, 2000: 21). Por ello, creemos que la lucha de Unamuno ha sido una lucha por hacer de España una gran democracia, donde todos los españoles deberían comprometerse con la realidad política de su país. Sin embargo, Unamuno, en su ensayo "Arabescos $I V$ », de 1913, no dejó de alertar acerca de los peligros inherentes a las democracias, sobre todo en pueblos poco instruidos, como era el caso del pueblo español finisecular.

Y luego, amigo mío y censor, puede darse el caso de que alguno de esos right man, hombres aptos, que se señalan a sí mismos su right place, el lugar para el que más aptitud crean tener, nos hable de la competencia relacionándola con la democracia. Pero la verdad, la verdad, sin mentir, acá para entre los dos, donde nadie nos oye, ¿no cree usted, amigo mío, que no le faltaba razón a Monsieur Faguet -creo que fue él- al decir que la democracia se distinguía por su culto a la incompetencia? (Unamuno, 1969b: 550).

Desde estos supuestos, Unamuno dirigió tres críticas a la democracia: la primera se refirió al electorado, la segunda al Parlamento y la tercera a la Constitución. Unamuno criticó, en primer lugar, el electorado, porque una democracia supone un país ilustrado, donde los mejores tienen la misión y, por qué no decirlo también, la obligación de gobernarlo. Sin embargo, en el periodo finisecular, las personas más cultas del país, así lo afirma Unamuno, parecían no sentir dicha 
responsabilidad social, colocándose al margen de la vida política del país (Unamuno, 1971: 199-200). En segundo lugar, criticó el Parlamento, por cuanto éste no representaba la opinión pública, en virtud de tender hacia un populismo que nada tenía que ver con los problemas reales de su España, ni de los españoles. No nos extraña, pues, que Unamuno criticase el populismo parlamentario tanto más cuanto creía que era «la opinión pública la que deber[ía] hacer [el] [...] Parlamento»y no éste a aquélla (Unamuno, 1968c: 1065). Y criticó, en tercer lugar, la Constitución, ya que, a su juicio, ésta no estaba, mínimamente, adaptada a las exigencias del país (Unamuno, 1969b: 1372).

En definitiva, la afirmación de la democracia fue la gran propuesta política, y quien dice política dice también educativa, de Unamuno. Según don Miguel, para que el régimen democrático pudiese implementarse, en su pleno sentido, eran necesarias tres cosas. Era necesario, en primer lugar, que cada uno de los partidos políticos edificase su identidad partidaria a partir de su propia ipseidad política, en vez de forjarla a través de la oposición hacia otro partido político. Era necesario, en segundo lugar, que el electorado fuese culto e instruido, ya que no podía haber una verdadera democracia si el pueblo no era capaz de elegir su propio destino a raíz de su incultura y retroceso cultural. Y era necesario en tercer lugar que el Parlamento y la Constitución lo fuesen en la verdadera acepción de la palabra, ya que, a su juicio, el Parlamento debería ser, por 
antonomasia, la «casa del pueblo» (Roberts, 2007: 184) y la Constitución el conjunto de las leyes fundamentales del país.

\section{El Estado: la separación entre el «Trono» y el «Altar»}

$\mathrm{Ni}$ la Iglesia católica se instituyó para promover la cultura, ni las órdenes religiosas que de ella han nacido tienen por misión hacer ni deshacer patrias, ni la Iglesia misma debe tener que ver con disputas de príncipes y de Estados. La alianza entre el Altar y el Trono es, a la larga, fatal a uno y a otro (Unamuno, 1966:1111).

La sociedad española finisecular era una sociedad fuertemente sacralizada, donde la unión entre el «Altar» y el «Trono» era aceptada por la mayoría de la población, sobre todo por la rural. Esta misma percepción de la realidad la analizó y comentó Unamuno en su novela Paz en la guerra, de 1897, donde, bajo el lema «Dios, Patria y Rey», dibujó su personaje Ignacio, según el principio político-religioso de que el «Rey [es] el brazo [derecho] de Dios» sobre la tierra (Unamuno, 1967: 124). Sin embargo, ésta no es la posición de nuestro autor que, al rechazar la sacralización de la sociedad, opta, de forma decidida, por su secularización o, si se quiere, por su laicización. 
Unamuno planteó y desarrolló, por primera vez, dicho tema en su ensayo Región y Patria, de 1900, cuyo sugestivo título nos ubica, desde el primer momento, en el centro del problema. En la España de finales del siglo XIX y principios del XX, se debatía el problema de si el arzobispo fray Bernardino Nozaleda debería ser o no nombrado arzobispo «para la sede arzobispal de Valencia». En la génesis del mencionado problema radicaba el hecho de que muchos españoles acusasen a fray Bernardino de «mal patriota»e, incluso, de «traidor a la patria» a raíz de su conducta como arzobispo de Manila (Unamuno, 1966: 1108). Sin embargo, Unamuno no aceptaba dicha crítica, ya que consideraba que las órdenes religiosas no tenían la finalidad de ayudar a la patria a concretar sus intereses políticos sino la de salvar las almas individuales (Unamuno, 1966: 1110). No nos extraña, pues, que, para Unamuno, la misión de la Iglesia, en Filipinas, no fuese la de «hacer españoles» o la de sostener la soberanía española, sino la de «hacer cristianos católicos» (Unamuno, 1966: 1110).

Para Unamuno, había razones históricas que han fundamentado, tradicionalmente, la unión del «Trono» $\mathrm{y}$ del «Altar». Y una de ellas, y quizás la más decisiva, fue la unión político-religiosa del país contra los moros (Unamuno, 1971: 222). Fueron los ocho siglos de lucha contra los moros, pues, los que hicieron que, a su juicio, los sentimientos patriótico y religioso se hayan unificado (Unamuno, 1966: 1108) de forma, abusivamente, 
coextensiva (Unamuno, 1971: 223). Dicha unión, según nuestro autor, era tanto más aceptada por todos cuanto que, para algunos miembros de la Iglesia, el catolicismo era lo «más castizo» dentro de la propia hispanidad (Unamuno, 1966: 1113). Empero, hay otra razón que no puede ser olvidada. Nos referimos, en concreto, a la «romanización de la cristiandad». Fue con Constantino, en el siglo IV, cuando se unificaron el «Trono» y el «Altar», y empezó la sacralización de la sociedad (Unamuno, 1969b: 334). No nos extraña, pues, que Unamuno hallase en estos dos motivos históricos las dos razones fundamentales para la fuerte sacralización de su España finisecular.

Sin embargo, como ya hemos puntualizado, ésta no es la posición de nuestro autor, que abogó por la secularización de la sociedad española. Lo demuestra su novela San Manuel Bueno, mártir, de 1931, donde Unamuno, a partir de su anarquismo religioso, afirmó que la religión nada tiene que ver con los problemas económicos y políticos de cada país. La legitimación teórica de dicha toma de posición la creyó hallar en dos pasajes del Evangelio, en los que Jesucristo afirmó: (1) «Dad al César lo que es del César y a Dios lo que es de Dios» (Unamuno, 1966: 1111) y (2) «Mi reino no es de este mundo» (Unamuno, 1970: 810). Pero hay, todavía, otro pasaje del Evangelio que Unamuno utiliza para legitimar su concepción secularizada de la sociedad. Nos referimos al pasaje bíblico donde los escribas y fariseos acusaban a Jesús de mal patriota, en la medida en que éste 
no se resignaba a mezclar los asuntos del Estado con los de la Iglesia (Unamuno, 1969b: 335). Pues bien, fue precisamente a partir de la conjunción de estos tres pasajes bíblicos que don Miguel legitimó su toma de posición, que, en este aspecto, coincide con la propia posición políticoreligiosa de Jesucristo.

Y en cuanto a eso del sindicato es en ti un resabio de tu época de progresismo. No, Lázaro, no; la religión no es para resolver los conflictos económicos o políticos de este mundo que Dios entregó a las disputas de los hombres. [...] Yo no he venido a someter los pobres a los ricos, ni predicar a éstos que se sometan a aquéllos. Resignación y caridad en todos y para todos. Porque también el rico tiene que resignarse a su riqueza, y a la vida, y también el pobre tiene que tener caridad para con el rico (Unamuno, 1967: 1146).

Empero, lo antedicho impone una cuestión esencial. Si el «Trono» y el «Altar» son dos esferas distintas, con implicaciones, igualmente, distintas, ¿cómo pensarlas si las dos forman parte de la realidad social de un país? Unamuno contestó, por primera vez, a esta cuestión en el susodicho ensayo de 1900, cuando afirmó que las dos esferas pueden coexistir, siempre y cuando la religión se abstenga de entrometerse en todas las cuestiones económicas y políticas de los Estados, observando, únicamente, el modus vivendi del pueblo cristiano (Unamuno, 1966: 1115). Sin embargo, 
Unamuno terminó por radicalizar su toma de posición cuando, en su La agonía del cristianismo, de 1924, planteó el mismo problema; pero, ahora, en términos agónicos. En dicha ocasión, el rector salmantino, al rechazar la tesis del «reinado social de Jesucristo», defendida por los jesuitas (Unamuno, 1969b: 336), afirmó que el cristianismo es, esencialmente, individualista (Unamuno, 1969b: 340) y antihistórico (Unamuno, 1969b: 336), y que por ello es, esencialmente, contrario a la sociedad y a la historia. De este modo, consideró que sólo el ermitaño, el que vive solo, se aproxima al ideal cristiano (Unamuno, 1969b: 340). Pero, como es imposible vivir de esta forma individualista $y$ antihistórica, el cristianismo supone, a su juicio, la afirmación de una existencia agónica, es decir, de una existencia dentro de una comunidad y de la historia.

Pero como el cristiano es hombre en sociedad, es hombre civil, es ciudadano, ¿puede desinteresarse de la vida social y civil? ¡Ah!, es que la cristiandad pide una soledad perfecta; es que el ideal de la cristiandad es un cartujo que deja padre y madre y hermanos por Cristo, y renuncia a formar familia, a ser marido y a ser padre. Lo cual, si ha de persistir el linaje humano, si ha de persistir la cristiandad en el sentido de comunidad social y civil de cristianos, si ha de persistir la Iglesia, es imposible. Y esto es lo más terrible de la agonía del cristianismo (Unamuno, 1969b: 336). 
Desde un punto de vista pragmático, la secularización propuesta por Unamuno supone dos cosas. En primer lugar, la disociación entre el matrimonio civil y el matrimonio religioso, de tal forma que puede contraerse el primero sin necesidad de contraer el segundo. Lo que implica tanto como decir que, para Unamuno, la esfera espiritual es distinta de la esfera social y que las faltas espirituales no pueden tener más que sanciones espirituales (Unamuno, 1971: 223). Y después, la desnacionalización de los frailes. Para Unamuno, todos los que integran órdenes religiosas deberían ser considerados extranjeros en todos los países, no teniendo ni los deberes ni los derechos de los demás ciudadanos (Unamuno, 1966: 1115).

En definitiva, la sociedad española de finales del siglo XIX y principios del XX era una sociedad fuertemente sacralizada, donde se mezclaban las realidades del Trono y del Altar. Los motivos de dicha secularización radicaban, primero, en la unificación de dichas realidades hecha por Constantino, en el siglo IV y, después, en los ochos siglos de lucha contra los moros. Sin embargo, otra es la propuesta de Unamuno, que defiende la secularización de la sociedad y la disociación entre el «Trono» y el «Altar». La justificación de su toma de posición la buscó en el propio Evangelio, donde Jesucristo afirmó, contundentemente, primero, (1) «Dad al César lo que es del César y a Dios lo que es de Dios» $y$, después, (2) «Mi reino no es de este mundo». Unamuno, al asumir como suyo dicho supuesto teórico, se 
acercó a una religiosidad existencialista, en la cual la religión pasó a ser pensada como un modus vivendi del pueblo cristiano. Dicha religiosidad acabaría por ser definida, en el año de 1924, en términos agónicos, ya que, para Unamuno, el ideal cristiano, el del ermitaño, individualista $\mathrm{y}$ antihistórico, supone una existencia dentro de una comunidad y de la historia.

3. El patriotismo: la necesidad de activación de la «raíz sensitiva» e «intelectiva» de la patria

Se me ha corroborado el sentimiento patriótico español por haber casado mucho más mi intuición patriótica, mi sentimiento primitivo y sensible de patria, es decir, el de mi patria chica, Bilbao, con el concepto patriótico deducido de mi consideración de la Historia de España. Y esto se ha cumplido merced a una noción de lo que el espíritu de mi pueblo nativo y el de mi casta vascongada pueden ser y significar en el concierto y el porvenir del espíritu nacional (Unamuno, 1966:1288-1289).

Si hay una actitud política inmutable en Unamuno ésta es sin duda la de su patriotismo. Sin embargo, el patriotismo unamuniano no es de carácter militarista, al cual se opuso, determinantemente, desde el primer momento. Así lo atestigua su ensayo La crisis del actual patriotismo español, de 
1905, donde nuestro autor afirmó, de forma contundente, que «hay que reaccionar contra la tendencia a que eso que se llama la religión del patriotismo asuma formas militares» (1966: 1286-1287). Prueba de ello fue su actitud de crítica siempre abierta hacia la dictadura de Primo de Rivera, que tuvo como consecuencia más visible su destierro voluntario en Fuerteventura, París y Hendaya, desde 1924 hasta 1931.

Ahora bien, si el militarismo es una forma condenable de patriotismo, ¿cómo pensarlo, entonces? Para Unamuno, «el patriotismo tiene dos raíces: [la] [...] sensitiva y [la] [...] intelectiva». Su raíz sensitiva se refiere a la patria que uno «puede [...] abarcar con la mirada» mientras que la intelectiva es la que se vincula con la historia nacional de cada país (1966: 1288). El sentimiento patriótico tiene, pues, estas dos raíces, las cuales deben fundirse, armoniosamente, entre sí. Sin embargo, en la España finisecular, se manifestaba un fenómeno de bipolarización entre «el sentimiento cosmopolita de humanidad y el apego a la [...] región nativa», cuyo resultado más nefasto se concretaba en el olvido de la raíz intelectiva de la patria. Para Unamuno, fue la interposición de dicho «sentimiento cosmopolita de la humanidad» entre la raíz sensitiva e intelectiva de la patria lo que hizo disolver su elemento intelectivo o histórico. No nos extraña, pues, que, a su juicio, el problema de los regionalismos finiseculares radicase en la falta de armonía entre las mencionadas raíces del patriotismo. Se observa un fenómeno de polarización, 
consistente en que van creciendo paralelos el sentimiento cosmopolita de humanidad y el apego a la pequeña región nativa. El regionalismo se acrecienta de par con el cosmopolitismo, a expensas del sentimiento patriótico nacional, mal forjado por la literatura erudita y la historia externa. A medida que se ensancha la gran Patria Humana, se reconcentra lo que aquí se llama patria chica o de campanario. Parece como que se busca en el apego al terruño natal un contrapeso a la difusión excesiva del sentimiento de solidaridad humana [...]. Se concentra la intuición sensible de patria a medida que se abstrae el concepto de ella, lo cual quiere decir que no están en perfecta compenetración y armonía. Y no lo están, seguramente, por culpa de la presión coercitiva y bárbara que se ha empeñado en casarlas en la historia según intereses de clase (1966: 1288).

Para Unamuno, no obstante, el motivo ya invocado, existían dos razones más para el surgimiento de los regionalismos en España: la primera se refiere al anti-castellanismo y la segunda a la Iglesia. Según el autor, los regionalismos catalán, vasco y gallego no eran más que una expresión de la «profunda aversión al espíritu castellano y a sus manifestaciones [culturales y políticas]» (1966: 1289); aversión que se fue consolidando, en la historia, a través del «sentido católico-conservador», que, al ser contrario a las «grandes nacionalidades», se empeñó en separar a los pueblos (1966: 1296). No nos extraña, pues, que Unamuno 
no dejase de expresar, laudatoriamente, su afinidad hacia el espíritu castellano, así como a su intento de unificación nacional, ya que dicha región, y éste es su parecer, no hizo más que intentar poner su sello en todas las manifestaciones culturales, tratando de castellanizar el país (1966: 1289). Su aprecio es tanto mayor cuanto que exhortó a las demás regiones a hacer lo mismo. Para Unamuno, sólo cuando todas las regiones españolas intenten imponerse, espiritualmente, sobre las demás podría formarse la patria española (1966: 1291). De este modo, para Unamuno, Cataluña debería tanto tratar de catalanizar España, como el País Vasco y Galicia, tratar de vasconizarla y galleguizarla, respectivamente.

Castilla ha cumplido su deber para con la patria común castellanizándola todo lo que ha podido, imponiéndole su lengua e imponiéndosela a otras naciones, y ello es ya una adquisición definitiva. El deber de Cataluña para con España es tratar de catalanizarla, y el deber para con España de parte de Vasconia es el de tratar de vasconizarla (Unamuno, 1966: 1297).

Con dicha toma de posición, Unamuno pretendió formular una nueva concepción del regionalismo español que contrasta, desde el primer momento, con la concepción tradicional del mismo. Si la concepción tradicional es una concepción, eminentemente, negativa, donde cada región se opone, ciegamente, a las demás regiones (Unamuno, 1971: 111), la 
concepción unamuniana supone a contrario sensu la interacción entre todas las regiones (Unamuno, 1971: 112). La propuesta unamuniana es bastante sencilla. Para Unamuno, nada era más pernicioso que los pueblos encerrados en sí mismos, ya que este tipo de regionalismo, siendo "puramente defensivo», se basa en el «desconocimiento mutuo» (Unamuno, 1971: 216). Por ello, propuso un regionalismo generoso basado en la imposición mutua (Unamuno, 1971: 218), ya que sólo de este modo podrían percibirse las semejanzas que unen las diferentes regiones (Unamuno, 1971: 216-217) e incrementar sus identidades $\mathrm{o}$, si se quiere, sus personalidades. En este aspecto, la lectura que Unamuno hizo del saudosismo portugués terminó por reiterar su propia concepción del regionalismo (Unamuno, 1971: 218), ya que la independencia de Portugal del resto de la península hizo que la identidad patria portuguesa, la personalidad del pueblo lusitano, fuese apagándose con el paso del tiempo (Unamuno, 1971: 218).

Para Unamuno, la mayor parte de los españoles no conocen su patria. Por ello, criticó a los bilbaínos y barceloneses que, sin conocer las demás regiones del país, como Aragón, Andalucía, Extremadura y Castilla, se iban de vacaciones por toda Europa (Unamuno, 1966: 281). Asimismo, si es cierto, como sostiene Stephen Roberts, que el regionalismo supone falta de conciencia histórica por parte de todos los españoles (Roberts, 2007: 172), cierto es también 
que la propuesta unamuniana para este problema consiste, igualmente, en la exhortación a hacer excursiones por todo el país, puesto que sólo de este modo los españoles podrían llegar a conocer y a amar a su patria. En su ensayo Excursión, publicado en su obra Por tierras de Portugal y España, en el año de 1911, Unamuno llegó a afirmar que deberían fomentarse sociedades de excursiones (Unamuno, 1966: 281), porque el conocimiento de la patria viene tanto del conocimiento de su historia, es decir, de su «alma», como del conocimiento de su geografía, esto es, de su «cuerpo» (Unamuno, 1966: 282). Sin embargo, la exhortación a las excursiones no es sinónimo de una exhortación a todo tipo de excursiones. Para Unamuno, nada era más censurable que las llamadas excursiones de lujo, las de los turistas deportivos (Unamuno, 1966: 282283), que viajaban por «las grandes rutas ferroviarias», que dormían en «cama[s] de hotel» y que comían «comida internacional», ya que por las mismas no había contacto ni con el pueblo ni con la tierra patria (Unamuno, 1966: 281). En lo que concierne al tema, es interesante notar que Unamuno fue gran un adepto de las excursiones, y que las hizo a caballo, a burro y a pie; y a través de éstas buscó conocer nuevos pueblos y rincones de España. En el mencionado ensayo, refiriéndose a sus excursiones a la Sierra de Gredos escribió lo que transcribimos a continuación: 
En mi vida olvidaré una noche en que, durmiendo sobre el santo suelo de mi Patria, sobre la tierra misma, en una de las cumbres españolas, me sorprendió antes del alba una tormenta. Viendo ceñir los relámpagos a los picachos de Gredos se me reveló el Dios de mi Patria, el Dios de España, como Jehová se les reveló a los israelitas tronando y relampagueando en las cimas del Sinaí. La revelación de Dios baja de las montañas (Unamuno, 1966: 285).

En definitiva, según Unamuno, el «sentimiento patriótico español» no pudiendo edificarse a partir de ningún tipo de «militarismo», debería fundarse más bien a partir de la perfecta unión de sus «bases sensitivas», de apego a la tierra natal, e «intelectiva», de amor a la historia común. Sin embargo, en la España de finales del siglo XIX y principios del XX, el «sentimiento cosmopolita de la humanidad» tendía a echar en el olvido la mencionada base intelectiva, haciendo surgir los regionalismos por la falta de una base histórica que unificase a todos los españoles. Para Unamuno, la Iglesia y el anti-castellanismo fueron dos factores determinantes para la irrupción de los regionalismos finiseculares. En primer lugar, porque la Iglesia siempre estructuró su política internacional a partir de la máxima «dividir para reinar» $\mathrm{y}$, después, porque Castilla siempre intentó imponerse política y culturalmente sobre las demás regiones. Ahora bien, si con respecto a la Iglesia la actitud de Unamuno fue la de rechazo a su forma 
de concebir la política internacional, con respecto a Castilla y a su política nacional fue la de plena aprobación. Para Unamuno, todas las regiones españolas deberían hacer lo mismo que hizo Castilla a lo largo de los siglos, esto es, intentar sellar las demás regiones con su propio espíritu. De este modo, de la misma forma que Castilla intentó castellanizar el país, imponiéndose a las demás regiones, así deberían hacer, igualmente, Galicia, el País Vasco y Cataluña, intentando galleguizar, vasconizar y catalanizar a toda a España. No nos extraña, pues, la lectura crítica que Unamuno hizo del saudosismo portugués, ya que consideró que la independencia de Portugal del resto de la península fue la causa del enflaquecimiento del espíritu del pueblo luso. En lo que concierne al tema, cabría añadir, tan sólo, que, para Unamuno, las excursiones, hechas a caballo, a burro y a pie, eran una de las formas más proficuas para la activación del patriotismo, ya que a través de las mismas los españoles podrían conocer mejor el cuerpo de su patria. En este aspecto, podría decirse que, para Unamuno, el conocimiento del cuerpo, es decir, del territorio español, constituía la condición de posibilidad del conocimiento de su idiosincrasia, esto es, de su alma. 


\section{Conclusiones}

Como hemos referido al principio del presente estudio, la elección de los conceptos unamunianos de «democracia», «Estado»y «patriotismo» no fue casual ni fortuita, ya que a través de los mismos hemos pretendido buscar fundamentación teórica para analizar la realidad política, social y económica que nos rodea.

Como Unamuno vio tan oportunamente, una democracia sólo es posible si el pueblo es «el guía de su propio destino», ya que una democracia sin un electorado instruido se transforma en una odiosa demagogia a partir de la cual los partidos políticos buscan votos, con mayor o menor moralidad política, con vistas a la búsqueda del poder, del eterno poder que tanto seduce. Asimismo, cabría preguntar si hoy en nuestras sociedades casi sin analfabetos absolutos pueden nuestras democracias constituirse como regímenes del pueblo por excelencia. ¿Será hoy el pueblo «el guía de su propio destino» como tanto deseó Unamuno? Si somos rigurosos: no. El "pueblo" todavía no es soberano; y no lo es porque no tiene los conocimientos necesarios para decidir conscientemente sobre los temas políticos, económicos y sociales de su país. Y lo que es más lamentable, es que dicha incapacidad no radica sólo en la población que se ubica entre los 60 y 90 años, que sólo hizo la escolarización primaria, sino, y sobre todo, en los jóvenes que salen de nuestras universidades. ¿Qué porcentaje de 
jóvenes que han salido de nuestras universidades conoce teorías macro y microeconómicas para saber si determinada propuesta política que el candidato $\mathrm{A}, \mathrm{B}$ o $\mathrm{C}$ a presidente o a primer ministro es ejecutable? Diríamos, siendo optimistas, que muy pocos. Y si se traslada la reflexión de la «economía» a la «política», ¿qué jóvenes que han salido de nuestras universidades conocen la diferencia entre los partidos que se ubican a la izquierda o la derecha, sus orígenes y sus familias políticas, así como sus idearios, en una palabra, las bases de la vida política consciente y reflexionada? Y nos hallamos angustiosamente con la misma respuesta: «muy pocos». $\mathrm{Y}$, por último, en el campo de la fundamentación ética, ¿qué porcentaje de jóvenes que han salido de nuestras universidades tiene bases éticofilosóficas para decir conscientemente acerca de temas tan importantes como aborto, eutanasia o clonación entre tantos otros temas bioéticos? Notamos una vez más tristemente que «muy pocos». Lo que cabe preguntar es si la escuela cumple con su misión de educar a nuestros jóvenes. Y, al preguntarlo, llegamos a la angustiosa conclusión, y lo afirmamos en la misma línea de Unamuno, que la escuela al intentar hacer especialistas (Fachmann) se olvidó del caballero culto y fino (Gentleman). No estaría mal que en nuestros bachilleratos, para no decir universidades, también, hubiese tres disciplinas comunes a todos los alumnos: la de economía, la de política y la de ética. Con respecto al hecho de que la política sea más un juego de 
antagonismos que una defensa de ideales, creemos que esta triste realidad cambiaria si el pueblo fuese culto y no se permitiese oír necedades.

Con respecto a la defensa de la separación entre el «Trono»y el «Altar» la historia ha dado razón a Unamuno. Si algo está en las raíces del fundamentalismo religioso contemporáneo, de la barbarie de los atentados, es, aunque no exclusivamente, la triste unión entre el poder temporal y el poder espiritual. La defensa de Estados secularizados es una exigencia que se debe plantear a todas las naciones. Porque, y como es bien sabido, en Estados sacralizados una ofensa civil es, al mismo tiempo, una ofensa religiosa. Y como sabiamente ha dicho Unamuno, no puede haber sanciones espirituales sino en el campo de la espiritualidad, como civiles en el campo de la civilidad. Querer mezclar ambos ámbitos es querer fomentar guerras religiosas $\mathrm{y}$ odios entre las naciones. $\mathrm{Y}$, claro, como se suele decir, no habrá paz entre las naciones mientras no haya paz entre las religiones. Hay, pues, un doble reto para la humanidad: la defensa de Estados secularizados y la búsqueda de paz entre las religiones.

Y, por último, si algo Unamuno antevió con claridad fue la disolución de la base intelectiva de las patrias a favor del sentimiento cosmopolita de la humanidad. En nuestra Europa, la creación de la Unión Europea, el logro más laudable después de la Segunda Guerra Mundial, ya que consiguió mantener y fomentar la paz entre nuestras 
naciones tan desgarradas por guerras, está teniendo el efecto de diluir la base intelectiva de las patrias. Empiezan más que nunca a sentirse conatos independentistas en las más diversas regiones, deseando la independencia de la patria a favor de una independencia integrada en la Unión Europea. Los efectos que estos conatos, si se concretan, podrán tener en la vieja estructura geopolítica mundial son difíciles de predecir, lo que sabemos es que algo cambiará. Lo que se nos ocurre decir es tan sólo lo que afirmamos a continuación de la mano del propio Unamuno: es increíble cómo el imperativo medieval religioso «dividir para reinar», obstaculizando las grandes nacionalidades, tiene todavía hoy hondas consecuencias. ¿Cuántos sin saberlo siguen un principio que ignoran pensando con ello que defienden su propio pensamiento? Esto de que el yo sea una individualización del espíritu colectivo, muchas veces manipulado por intereses individuales y particulares mezquinos, tiene implicaciones políticas que todavía hoy se hacen sentir.

\section{Bibliografía}

Aubert, P. (2005). Miguel de Unamuno y la política: de la predicación cívica a la disidencia. En Chaguaceda, A. (ed.). Miguel de Unamuno. Estudios sobre su obra. II, 
Actas de las $V$ Jornadas Unamunianas. Salamanca: Ediciones Universidad de Salamanca.

Azaola, J. M. (1996). Unamuno y sus guerras civiles. Bilbao: Ediciones Laga.

Béracoud, J. (1965). Miguel de Unamuno y la Segunda República. Madrid: Taurus.

Blanco, C. (1966). El socialismo de Unamuno: 1894-1897. Revista de Occidente 41, 166-184.

Cacho, V. (1997). Repensar el noventa y ocho. Madrid: Biblioteca Nueva.

Calvo, J. L. (1998). La cara oculta del 98: Místicos e intelectuales en la España del fin de siglo (1895-1902). Madrid: Cátedra.

Delgado, B. (1973). Unamuno educador, Madrid: Editorial Magisterio Español.

Díaz, E. (1968). Revisión de Unamuno. Análisis crítico de su pensamiento político. Madrid: Tecnos.

Ereño, J. A. (2008). El pensamiento socialista de Unamuno en La lucha de clases (1894-1897). En Chaguaceda, A. (ed.). Miguel de Unamuno. Estudios sobre su obra. III. Salamanca: Ediciones Universidad de Salamanca.

Fox, I. (1997). Unamuno y el nacionalismo: En torno al casticismo y la identidad nacional. En Berchem, Th., y Laitenberger, H. (coords.). El joven Unamuno en su época: Actas del coloquio internacional Wurzburg 1995. Valladolid: Junta de Castilla y León / Consejería de Educación y cultura. 
García, G. (1988). Los intelectuales y la dictadura de Primo de Rivera. Madrid: Alianza Editorial.

Gómez de la Torre, I. B. (2000). Unamuno y la Universidad: rector e intelectual. En Flórez, C. (coord.). Tu mano es mi destino. Salamanca: Ediciones Universidad de Salamanca.

Gómez, M. D. (1986). Unamuno y la polémica sobre la autonomía universitaria. En AA. VV., Perspectivas de la España Contemporánea. Estudios en homenaje al profesor V. Palacio Atard. Madrid: Guthersa.

Luján, E. (2009). Unamuno y el pensamiento liberal: los inicios de una larga y peculiar relación. En Chaguaceda, A. (ed.). Miguel de Unamuno. Estudios sobre su obra. IV. Salamanca: Ediciones Universidad de Salamanca.

Morón, C. (1997). «Alma nacional»: el trasfondo sociológico de En torno al casticismo. En Berchem, Th., y Laitenberger, H. (eds.). El joven Unamuno en su época. Actas del coloquio internacional Wurzburg 1995. Valladolid: Junta de Castilla y León - Consejería de Educación y cultura.

Pérez, R. (1973). Política y sociedad en el primer Unamuno (1894-1904). Barcelona: Ediciones Ariel.

Rivero, M. A. (2008). Desarrollo político en el joven Unamuno. Antecedentes de su etapa socialista. En Chaguaceda, A. (ed.). Miguel de Unamuno. Estudios 
sobre su obra. III. Salamanca: Ediciones Universidad de Salamanca.

Roberts, S. (2007). Miguel de Unamuno o la creación del intelectual español moderno. Salamanca: Ediciones Universidad de Salamanca.

Roberts, S. (2007). Miguel de Unamuno y su relación con el socialismo entre 1914-1924: una primera aproximación. Cuadernos de la Cátedra Miguel de Unamuno 1 (43), 89-98. Romero, L. (ed.) (1998). El camino hacia el 98: los escritores de la restauración y la crisis del fin de siglo. Madrid: Visor. Salcedo, E. (2005). Vida de don Miguel: Unamuno, un hombre en lucha con su leyenda. Salamanca: Globalia Ediciones Anthema.

Unamuno, M. (1966). Obras Completas I. Madrid: Escelicer. Unamuno, M. (1967). Obras Completas II. Madrid: Escelicer. Unamuno, M. (1968a). Obras Completas III. Madrid: Escelicer.

Unamuno, M. (1968b). Obras Completas IV. Madrid: Escelicer.

Unamuno, M. (1968c). Obras Completas V. Madrid: Escelicer. Unamuno, M. (1969a). Obras Completas VI. Madrid: Escelicer.

Unamuno, M. (1969b). Obras Completas VII. Madrid: Escelicer.

Unamuno, M. (1970). Obras Completas VIII. Madrid: Escelicer.

Unamuno, M. (1971). Obras Completas IX. Madrid: Escelicer. 
Unamuno, M. (2003). Artículos desconocidos en «El mercantil valenciano» (1917-1923). Valencia: Biblioteca Valenciana.

Urrutia, M. M. (1997). Evolución del pensamiento político de Unamuno. Bilbao: Universidad de Deusto. 